\title{
Carbon Monoxide as Indoor Pollutant in Kano Metropolis
}

\author{
${ }^{1}$ AYODELE, $\mathbf{J} . \mathrm{T} ;{ }^{2}$ ADEKIYA, A O $;{ }^{2}$ YAKUBU, I \\ ${ }^{1}$ Department of Chemistry and ${ }^{2}$ Department of Geography, Bayero University P.M.B.3011. Kano, Nigeria
}

\begin{abstract}
The level of carbon monoxide concentrations in three different residential areas of Kano municipality has been determined. Health effects of carbon monoxide are not only determined by its pollution level, but the time spent breathing polluted air. Samples of carbon monoxide gas in three different residential districts within the Kano Metropolis; the high (city), medium (Sabon gari) and low (Nassarawa) density residential districts were assessed. The frequency distribution pattern for the gas is skewed towards high frequency of low concentration with a mean and standard deviation of $4.93 \pm 3.08 \mu \mathrm{g} / \mathrm{m}^{3}$. Evidence linking high level of indoor carbon monoxide to low birth weight and increase in prenatal deaths necessitates the need to periodically check the levels of the gas within each house hold in the metropolis. @JASEM
\end{abstract}

The breathing of safe air is as important as safe water or food, but many women and children in developing countries are compelled to breathe polluted air resulting from biomass combustion (Albalak et al., 1999). People in developing countries rely on coal and biomass in the form of wood, dung and crop residues for domestic energy. These materials are burnt indoors in open fires or poorly functioning stoves (Bruce et al.,1998). In indoor environment, individuals are exposed to carbon monoxide from sources such as domestic fuel burning and gas cooking appliances Carbon monoxide is an odourless, colourless, toxic gas produced in the process of incomplete combustion of fuel resulting from poorly ventilated kerosene or gas space heater, leaking chimneys and furnaces, gas water heaters, wood stoves, fire places, gas stoves, generators and other gasoline powered equipments, automobile exhausts and tobacco smoke (De Koning et al., 1985).

The health effects associated with exposure to carbon monoxide at low concentration include fatigue and chest pain in people with heart disease (WHO, 2004). At higher concentration, impaired vision and coordination, headaches permanent damage to central nervous system dizziness, confusion, nausea, and death may occur. At moderate concentration, impaired vision and reduced brain function may occur. In pregnancy it results in low birth weight and prenatal death (USEPA, 1997, Raub et al., 2000; WHO, 2004). Health effects of carbon monoxide are not only determined by its pollution level, but the time spent breathing polluted air. There is paucity of information on indoor levels of carbon monoxide in Nigeria and in many developing countries (Raub et al., 2000). Therefore the aim of this paper is to provide a baseline data of carbon monoxide level in Kano city of Nigeria. The fatal cases of carbon monoxide poisoning are often grossly under-reported or mis-diagnosed by medical professional (Raub et al., 2000). In developing countries people spend from $3-7$ hours daily exposed to high level of pollution. This paper examines indoor levels of carbon monoxide in Kano Metropolis.

\section{MATERIALS AND METHODS}

A total of 275 samples were taken between Feb April 2006. Carbon monoxide concentrations were measured in different parts of Kano municipality. All indoors were nonsmokers in all the six residential regions of the municipality. Indoor samples were collected with sampling times beginning or ending at $8.00 \mathrm{am}$ or $8.00 \mathrm{pm}$ For the indoor sampling automatic samplers were clipped on a camera tripod and placed a metre from the walls, windows, air-conditioners and other ventilation devices to avoid excess airflow. Samplers were located $1.2 \mathrm{~m}$ above the floor so that carbon monoxide concentrations were measured at about the sitting and breathing zone.

Hydrogen sulphide in air was developed and applied by Natush et al., (1972). Carbon monoxide was removed from air samples by passing the air through fitted bubblers designed by Warlburg et al (1969). This paper reports level of carbon monoxide in different parts of Kano Municipal environment using automatic gas sensors

Samples of carbon monoxide were measured from different locations in the municipality as shown in Fig 1. A total of two hundred and seventy samples were taken between October, 2005 and March 2006 on a continuous basis through out the sampling period. The sampling sites are as shown in Fig 1 . Kano City is located at the heart of the Metropolis. Sabon - Gari is located west while Brigade, is located north-west of the airport. Nassarawa (GRA) is east of the City. 


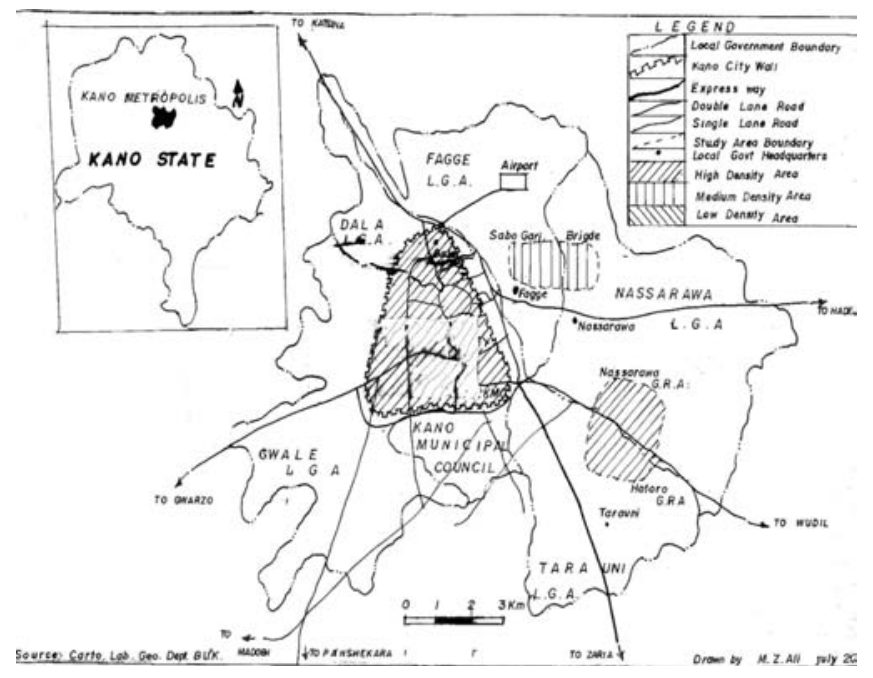

Fig 1 Sampled Residential Districts in Kano Metropolis

Instrumentation: The Crowcon - Gasman "FL" and "TO" Detection Instruments were used. The Gasman "FL" is designed to monitor for the presence of flammable gases, and is certified to EEx IA 11C T3/T4 while the Gasman "TO" is designed to monitor for the presence of specific toxic gases, and is certified to EEx IA IIC T3/T4. Temperature classification T3 applies if the unit is fitted with the Crowcon rechargeable battery pack, with $\mathrm{T} 4$ applies if the unit is fitted $\mathrm{i}^{\text {th }}$ disposable batteries. To adjust the span of the "TO" and "FL" versions gas of known concentration and reliable delivery systems to the sensor are required. The calibration gas test kits, comprising gas mixtures, either in disposable cylinders, regulator, and tube and calibration adaptors were used the calibration adaptor was fitted into to top of the sensor housing and the gas cylinder value was opened. The gas flow rate was set to sensor $0.5 \mathrm{~min}$ and the reading on the display was allowed to stabilize. The CAL preset was adjusted so that the display indicated the concentration shown on the cylinder. With the unit now placed in normal air, the switch was turned to the GAS position. The green LED and the sounder (if factory set) operated once a second. The LCD display showed 000 for "TO" and "FL" versions. If not removed the black cover below the display was adjusted to ZERO preset until the display was 000. (for "TO or "FL" versions). It was ensured that the cover was placed after adjustments were made.

\section{RESULTS AND DISCUSSION}

The indoor levels of carbon monoxide in the three different residential districts in the metropolis are shown in Fig 2 (2-5).Fig 2 shows the general scenario of the gas within the metropolis. The frequency distribution pattern for the gas is skewed towards high frequency of low concentration with a mean and standard deviation of $4.93 \pm 3.08 \mu \mathrm{g} / \mathrm{m}^{3}$ (Table 1). The frequency distribution pattern for the gas within the city (inner core) is high with a mean and standard deviation of $5.14 \pm 3.90 \mu \mathrm{g} / \mathrm{m}^{3}$ (Fig 3). The home environment within the city is poor. Housing conditions are poor and substandard. Significant portions of the cooking take place in conditions were much of the air borne effluents are released into the living area. People in the inner core of the city rely on coal, wood dung, and crop residues for domestic energy .The frequency distributing pattern for the gas in Sabon Gari (Fig 4) is skewed towards high frequency of low concentration with a mean and standard deviation of $5.49 \pm 3.41 \mu \mathrm{g} / \mathrm{m}^{3}$. Housing condition in Sabon Gari is poor, occupancy ratio within individual household is high Average of about 4-6 persons per room. The main source of domestic energy is kerosene, wood and coal. It was observed during sampling, that other sources of indoor pollution were smokes from cars and motor-cycles as the area is characterized with high traffic flow.

The frequency distribution pattern for the gas in GRA is as shown in Fig 5 It is skewed towards high frequency of high concentrations with a mean and standard deviation of $3.31 \pm 2.61 \mu \mathrm{g} / \mathrm{m}^{3}$. The observed distribution pattern has been attributed to the use of fire wood to support gas stove as source of domestic energy. The large family system in Nigeria makes cooking to be done in large quantity. There is 
evidence linking high level of indoor carbon monoxide to low birth weight (fetal carboxyhaemoglobin) and increase in prenatal deaths, because carbon monoxide binds with hemoglobin to produce carboxyhaemoglobin, which reduces oxygen delivery to key organs and the developing fetus (Wang et al., 1997).

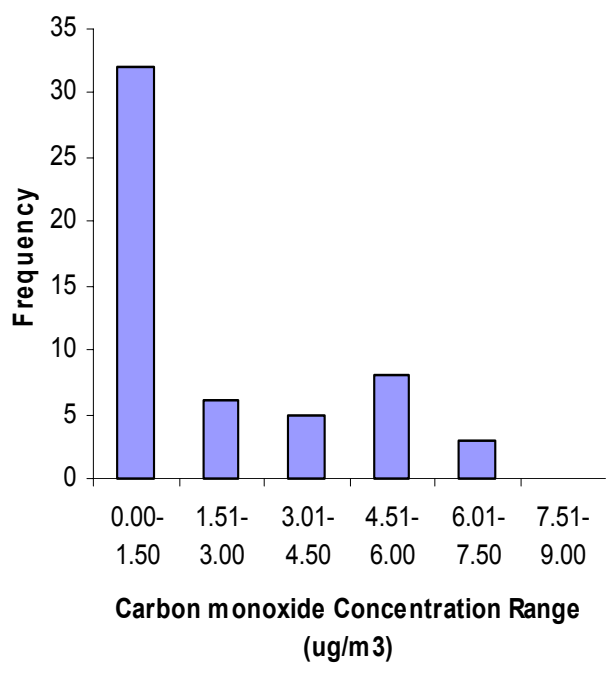

Fig 2: Frequency Distribution Pattern for carbon monoxide in Municipality

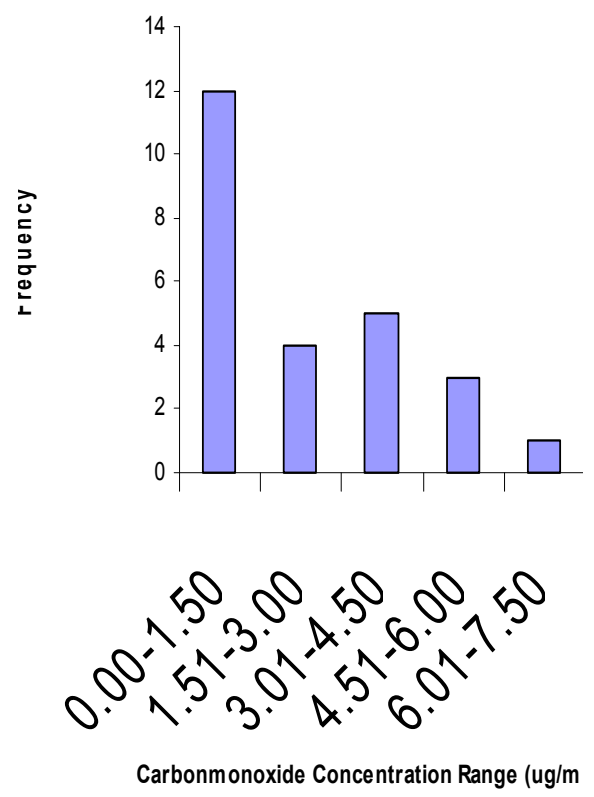

Fig 3: Frequency Distribution Pattern for carbon monoxide in City

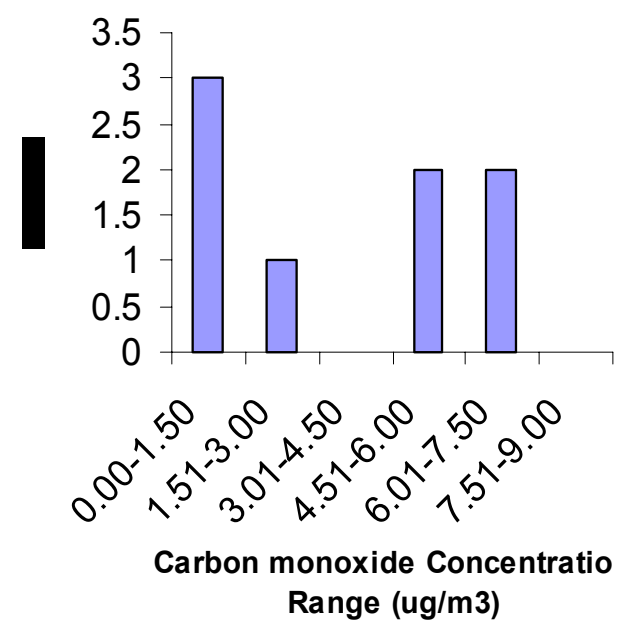

Fig 4: Frequency Distribution Pattern for carbon monoxide in Sabon gari

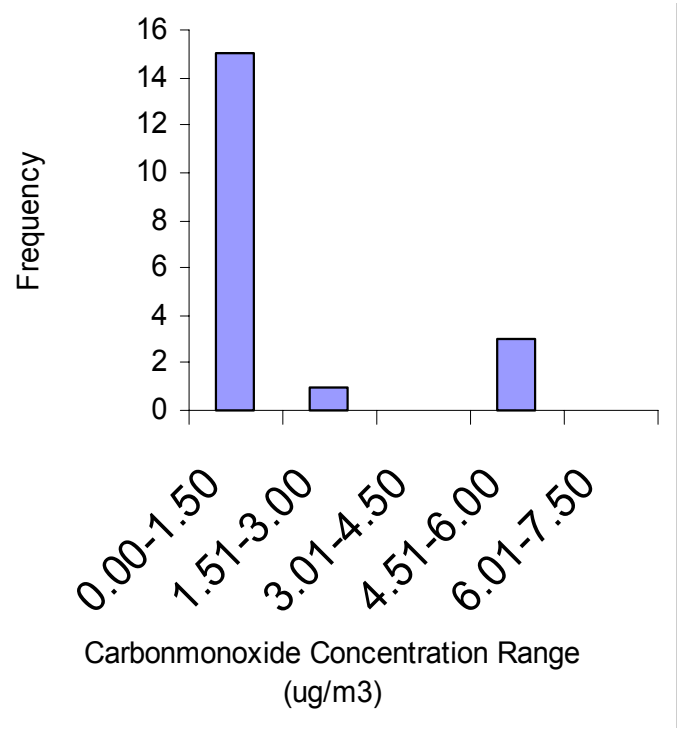

Fig 5: Frequency Distribution Pattern for carbon monoxide in GRA

Table 1: Indoor carbon monoxide concentration $\left(\mu \mathrm{g} / \mathrm{m}^{3}\right)$ within the three residential districts in Kano

\begin{tabular}{ll}
\hline Location & Mean \pm SD \\
\hline Municipality & $4.93 \pm 3.08$ \\
Inner core & $5.14 \pm 3.41$ \\
Sabon gari & $5.49 \pm 3.90$ \\
\hline Nassarawa & $3.31 \pm 2.61$ \\
\hline
\end{tabular}

Conclusion: Over the past years, transition to cleaner fuel among the poor has slowed down dramatically and there is coincidence that reliance on biomass is increasing among the poor in developing countries. (Bruce et al, 2000).Solid fuels are commonly burned 
in inefficient stoves and in poorly ventilated conditions (WHO 2004). Indoor air pollution in developing countries is a public health hazard for the poor, who are the most vulnerable people. Exposure to indoor pollution may be responsible for nearly 2 million deaths in developing countries and $4 \%$ of the global burden of disease (Bruce et al., 2000).

The close interrelationship between poverty and dependence on polluting fuels, and the importance of socio economic development should be at the core of efforts to achieve healthier house-hold environments (Bruce et al., 2002).

Acknowledgement: The authors express their gratitude to the Central Laboratory of Kano State Ministry of Environment.

\section{REFERENCES}

Albalak, R; Frisancho, ; Keeler, G.J (1999). Domestic Biomass Fuel Combustion and Chronic Bronchitis in two rural Bolivian Villages. Thorax, 54 (11); 1004-8.

Bruce, N; Neufield, L; Boy, E; West, C (1998). Indoor biofuel air pollution and respiratory health; the role of confounding factors among women in highland Guatemala. International Journal of Epidemiol, 27: pp 453-458

Bruce, N; Perez-Padilla, R; Albalak, R (2002) Indoor air Pollution in developing countries: A Major environmental and public health challenge. Bulletin of the World Health Organization 78 (9):1078-1089
Bruce, N; Perez-Padilla, R; Albalak, R (2002). The health effect of indoor air pollution exposure in developing countries World Health Organization protection of Human Environment .pp 7-30

Dekoing, HW; Smith, KR; Last, JM. (1985). Biomass Fuel combustion and health. Bulletin of the World Health Organization 63(1): 11-26.

Engel, P; Hurtado, E; Ruel, M (1998). Smoke exposure of women and young children in highland Guatemala predictions and recall accuracy. Human Organization; 54: 522-542

Raub, J. A; Mathieunoif, M ; Hampson, NB. ; Thom, SR. (2000) Carbon Monoxide poisoning a public Health perspective. Toxicology 145:1 - 14 .

United State Environmental Protection Agency (1997) Revisions to the National Ambient Air Quality Standards for Particular matter. Federal Register July 18, 62 (138)

Wang, X; Ding H; Ryan, L; Xu, X (1997) Association between air Pollution and low birth weight: a community - based study. Environmental Health Perspectives 105:514-520

WHO (2004).Indoor Smoke from solid fuel; assessing the environmental burden of disease. Environmental burden of diseases series No. 4 World Health Organization Publication Geneva pp 1-2 